Illustrations, though not exceptionally profuse, are clear and truly illustrate what they are intended to portray. The author is to be congratulated on producing a work of the utmost interest and value to all who are interested not only in tuberculosis but also in comparative pathology in its widest sense.

This volume will be widely read and highly appreciated in both medical and veterinary circles throughout the world.

Harold Burrow

\section{CRYSTAL STRUCTURES}

Structure Reports

Edited by A. J. C. Wilson. Vol. 8 : 1940-1941. Pp. viii $+384 . \quad 80$ Dutch florins. Vol. 9: 1942-1944. Pp. viii +448 . 65 Dutch florins. Vol. 15: 1951 . Pp. vii +588. 110 Dutch florins. (Utrecht: N.V. A. Oosthoek's Uitgevers Mij, 1956 and 1957.)

HE possibility of considering more than one volume of "Structure Reports" -intended as an annual reference work-in a single review is proof of the welcome fact that the editors are fulfilling their promise not only to keep the series up to date, but also simultaneously to bridge the gap of the war years. This gap is now happily closed with the appearance of Vol. 8, which contains such classical work as the structure of melamine (in which mathematical refinement techniques now in general use were first introduced), the observation that diffuse scattering is a widespread and informative phenomenon, and the X-ray studies of the phthalocyanines.

In all three volumes, as usual, the coverage is excellent, the format acceptable, and the information admirably distilled. The series now forms an excellent starting-point for the systematic analysis of the fruits of some forty years of international endeavour involving the determination of many hundreds of crystal structures - organic, inorganic and metallicby a variety of diffraction techniques, supplemented by such structural information as may be obtained from other disciplines like spectroscopy.

Published work has not been abstracted blindly. On the contrary, detailed assessments of each structure have been made, and critical comments are inserted by the editors where they have felt it necessary to do so. This critical analysis of published structures is a particularly valuable feature of the series. The vast amount of calculation necessary to extract the maximum information even from experimental data of only moderate quality makes it virtually certain that many published structures could be made to yield more accurate results than those with which one had to be satisfied before the advent of digital computers. On the other hand, high-speed computation allied with a failure to recognize the limitations of the data themselves merely permits us to reach a wrong answer faster than ever before.

Crystallographers generally are alive both to the potentialities and to the dangers of the present stage of development of the subject, and the standing of the editors in their own field is an adequate guarantee that non-crystallographers using these volumes will have the benefit of a sound assessment of the expanding stream of crystal structure analyses which look so impressive in the learned journals. Pondering the rapid increase in size and complexity of solvable structures, one is reminded of the optimistic adver. tisement- "the impossible we do at once; miracles take a little longer"; and miracles they truly are, for modern techniques are now carrying us, within the life-time of many of the original pioneers of X-ray crystallography, from the sort of crystals the structures of which a physicist can draw from memory to the sort of molecules which lie near the root of life itself. These volumes provide a worthy record of this continuing advance. It is a pity that their price makes them a luxury when their importance renders them a necessity.

H. J. Grenville-Wells

\section{METABOLISM OF THE NERVOUS SYSTEM}

Metabolism of the Nervous System

Edited by Derek Richter. Pp. xiv +600 . (London and New York: Pergamon Press, 1957.) $100 \mathrm{~s}$.

THE central nervous system provides more fascinating problems than any other part of the body and scientists all over the world are studying it from many points of view and travelling to meetings and symposia and congresses to discuss their results. These discussions often appear in book form and the present work is one of the most valuable of these books. It is based on the Second International Neurochemical Symposium, which was held at Aarhus, Denmark, in July 1956. It is divided into thirteen sections each dealing with a different aspect of the metabolism of the nervous system. Each section opens with a general review, which is followed by shorter and more specialized papers. There is so much that is valuable that it is impossible to mention more than a few examples of interesting contributions. There are some fine reproductions of pictures obtained with the electron microscope, there is a discussion by A. Engström of the use of X-rays to analyse structure, and a discussion of the bloodbrain barrier, and various other barriers. R. D. Keynes discusses electrolytes, F. Brink discusses nerve metabolism, S. S. Kety discusses the metabolism of the brain as a whole and J. H. Quastel discusses the metabolism of tissue preparations of brain. O. $\mathrm{H}$. Lowry describes experiments in which he dissects out single cells, weighs them and measures enzymes in them. As the total weight is often less than $0.01 \mu \mathrm{gm}$. this requires a rather special balance, but he hopes to extend his technique to single mitochondria.

R. V. Coxon, R. J. Rossiter, L. Einarson and H. Waelsch discuss the metabolism of carbohydrates, fats, nucleic acids and proteins respectively. W. Feldberg discusses acetylcholine, U.S. v. Euler and M. Vogt discuss noradrenaline, S. Udenfriend discusses 5-hydroxytryptamine and J. Crossland discusses all the other active substances which might possibly act as chemical transmitters.

It will be seen that this book covers a wide field, but only a small proportion of the papers have been mentioned; there are well over fifty altogether. It is a valuable guide to the results obtained by many different methods written by the leading authorities. Many of the papers are followed by short discussions, which help those who were not there to form a judgment of their importance. The book is beautifully produced but expensive. Libraries will have to buy it; individuals working in this field will buy it if they can afford it. 